Article

\title{
"They Came Home Over-Empowered": Identifying Masculinities and Femininities in Food Insecurity Situations in Tanzania
}

\author{
Michelle Bonatti ${ }^{1, *}$, Juliano Borba ${ }^{1}$, Izabela Schlindwein ${ }^{1}$, Constance Rybak ${ }^{1}$ and \\ Stefan Sieber ${ }^{1,2}$ \\ 1 SusLAND: Sustainable Land Use in Developing Countries, Leibniz Centre for Agricultural Landscape \\ Research (ZALF e. V), Eberswalder Str. 84, 15374 Müncheberg, Germany \\ 2 Department of Agricultural Economics, Humboldt University of Berlin, Rudower Chausee 16, \\ 10099 Berlin, Germany \\ * Correspondence: michelle.bonatti@zalf.de
}

Received: 29 May 2019; Accepted: 29 July 2019; Published: 3 August 2019

\begin{abstract}
Gender inequality, embedded in sociocultural structures, persists in Tanzania. It is particularly manifest in access to productive resources, income-generating and employment opportunities, time-use, and educational possibilities. Seeking to contribute to the study of gender roles in Tanzania in the context of food insecurity, this paper presents findings regarding the social role of gender drawn from a study of food security problems and family experiences in Dodoma, Tanzania. The methodology comprised two phases: (1) Face-to-face structured interviews with 333 households; and (2) workshops based on TO-Theater of the Oppressed. These two phases were complemented by repeated research stays in the Dodoma region. TO helps to understand the connections between the private universe of families and their narratives about food insecurity. From the voices of community members in Dodoma, we identify aspects of how men and women perceive the food insecurity situation. Results show that there are several contextual factors related to food insecurity at the community level, and that issues related to domestic violence also appear when cultural patrons and gender roles are questioned. Based on theory and the data collected, we seek not only to comprehend how food insecurity and gender roles are interconnected, but also how to think about new forms of public policies that support gender equality among men and women in rural areas. We conclude that transdisciplinary studies on food insecurity can help public policies address complex scenarios, comprising the multiple and conflicting values present in sociocultural issues, while taking into account individual community needs and specificities.
\end{abstract}

Keywords: gender inequalities; malnutrition; community perceptions; violence; hunger

\section{Introduction}

Food security projects are integrated into sustainable development, encompassing dimensions such as hunger, health, well-being, and gender equality, as well as climate action and conflicts/power relations. Thus, it is inherently complex and challenging to develop solutions and actions that improve the lives of those living in hunger while simultaneously addressing other challenges related to sustainable development. Therefore, projects must navigate a complex set of relationships between undernutrition, violence, food, and gender, among others. Engaging community voices about their own complex realities in this decision-making is critically important for understanding the possibilities of development as well as the causes and consequences of food insecurity and malnutrition for the lives of women and men [1]. 
Tanzania is primarily a rural country with an agriculture-based economy along with significant rural-urban and regional socio-economic disparities [2]. Here, poverty is primarily a rural issue [3]. Although some specific deprivations are higher in urban areas, generally, monetary deprivation and poverty are highest in rural areas, along with many life dimensions including nutrition, health, protection, education, information, sanitation, water, and housing). Eighty-one percent of rural children are deprived in three or more dimensions, while 33 percent live in poverty; only about 40 percent of urban children are deprived in three or more dimensions [4]. While there are several looming global crises, perhaps the most significant, longest lasting, and most endemic is the food security and chronic hunger crisis [5].

The current food insecurity is a consequence of many factors, including biophysical and social vulnerabilities related to climate change, water scarcity, increasing food prices, long-standing governmental neglect of agriculture, and gender inequality. Thus, when approaching the complex issue of food insecurity in Tanzania, it is important to address how these factors interact, including gender inequality [6].

Gender inequality, as embedded in sociocultural structures, persists in Tanzania, particularly in terms of access to productive resources, income-generating and employment opportunities, time-use, and educational possibilities [2]. Women play an important role in the food production process, as food producers, family food managers, and consumers. Although women are the major food producers, and thus, significant contributors to food availability, men continue to play a dominant role in the decision-making process. Traditionally, men are connected to the public world of work, while women are connected to the private world, such as childcare and housekeeping. Studies show that Tanzanian men have very traditional expectations regarding gender roles, while Tanzanian women have more dynamic expectations [7]. Women perform domestic (unpaid) work with the assistance of children [8]. The disconnect between their labor and financial rewards means that women are alienated and feel that their work is not equally valued. Typically, these women find themselves alone and without a network to share their concerns [7]. In some areas of Tanzania, when it comes to access to production resources, men control cash crops and women control food crops, thus reinforcing the unequal distribution of farming activities [8].

In response to these realities, international institutions, government, and civil society are focusing on women's issues. Although the term "empowerment" is commonly found on the international agenda, and within the scope of many projects, little is known about the social role of gender and food security programs for men in patriarchal villages in Tanzania. The social role of gender is a set of behaviours associated with masculinity and femininity. Societies have a gender system with different components and functions [9]. For Scott [10], gender is more than a learned identity; it is constituted and instituted through social relations, institutions, symbols, forms of social organization, discourses, and doctrines.

Often, food security and nutrition projects address individual outcomes, with most, but not all, focusing on the nutritional status of women and children. This focus on the nutritional status of women helps to identify possibilities for improving both their lives and their nutritional access [11]. However, in food security projects, the domestic environment (where the femininities and masculinities are expressed), along with its influence and interconnections with malnutrition, is little studied. As Lentz [1] pointed out, the pathways linking nutrition and domestic violence are often hypothesized, but not actually observed or reported; rather there is a tendency to understand correlations emerging from cross-sectional work as causal. While the women's empowerment movement undoubtedly advanced as a result, it had the unintended consequence of detaching violence against women from the broader struggle for social and economic equality, thus resulting in it being perceived as a female problem rather than a systemic problem affecting all individuals and social groups. Thus, there is a research gap with regard to empirically-based understandings of femininities and masculinities, along with their influence on, and interconnections with, malnutrition and food insecurity. 
This paper presents some of the findings regarding the social role of gender drawn from a study of food security problems and family experiences in remote rural zones of Dodoma, Tanzania. The objective was to contribute to the study of gender roles, food insecurity, and theirs interconnections in Tanzania. This research was driven by two research questions: First, how are Tanzanian subjectivities related to food insecurity and genders constituted and interrelated? Second, can these be better considered under the umbrella of food security projects?

A field study in the villages of Chinoje and Mzula, in the Dodoma region, provided us with empirical data that served as a basis for exploring these questions. The field activities, comprising 333 households in the first phase and 130 participants in the second phase, probed the food insecurity situation and its connections with the private universe of families at the community level. We identified some aspects of how men and women perceive the food insecurity situation, as well as possible solutions for their reality (their main problems), from the voices of community members in Dodoma. In parallel, we identified aspects of gender roles, i.e., masculinities and femininities, along with interconnections with malnutrition and food insecurity. This research focused on understanding community problems systemically, including interconnections as perceived by local citizens. Thus, the article does not focus separately on food security, masculinities, and femininities, but rather on how these are linked.

\section{Methodology}

\subsection{Description of the Research Area}

Modern Tanzania was formed in 1964 when the mainland country of Tanganyika merged with the newly independent island nation of Zanzibar. Each preceding nation had won its independence from Britain, Tanganyika in 1961 and Zanzibar in 1963 [12]. Much of modern Tanzania became a German colony in the 1880s, lasting through to 1920 when, under the Treaty of Versailles, it transitioned to a British colony. Both protectorates sought to "civilize" the local residents. Under the colonial administrations, the plantation economy in Tanganyika grew coffee, sisal, tobacco, cotton, and rubber-thus reducing food production by African families. Further, these families were removed from fertile land in order to provide open spaces for plantation agriculture. Forced to work for taxes, people faced severe penalties, including corporal punishment and imprisonment, for non-compliance. Thus, as people spent more time working on German plantations than on raising their own food crops, food and nutrition insecurity increased [12]. With independence, Tanzania's governance remained fragile, despite the relative success in building a nation. According to Maddox [13], the contradiction between capital accumulation in a global economy and political legitimation within the nation-state helps shape the contentious politics of citizenship and exclusion in postcolonial Africa.

Tanzania lies in East Africa with an estimated population of 44.9 million and an area of 947,300 square kilometers [14]. The population of Tanzania more than tripled between 1967 and 2012, soaring from 12.3 million to 44.9 million [14]. The population comprises more than 120 ethnic groups, of which the largest five are the Sukumas, Hayas, Nyakyusas, Nyamwezis, and Chagas $[15,16]$.

The study entitled, "Comprehensive Food Security and Vulnerability Analysis" [17] (URT/CFSVA, 2009), which analyzed livelihood-based food security and nutrition analysis with respect to the main pillars of food security [18] (FAO, 2008), showed that food producers in Tanzania were the most likely to be poor and to experience food insecurity out of all workers in all sectors of the economy. Thus, there is a strong need to focus more on tracking food insecurity and malnutrition as well as understanding the profile of the food insecure population in the country [17].

The Dodoma region (See Figure 1), where our case study is located, is at the geographic center of Tanzania, at latitude $6^{\circ} \mathrm{S}$ and longitude $35^{\circ}$ E. The town is $486 \mathrm{~km}$ (302 miles) west of Dar es Salaam and covers an area of 2669 square kilometers. Climatic conditions in Dodoma increase the risk of food insecurity due periods of drought. Dodoma features a semi-arid climate with relatively warm temperatures throughout the year. The region averages $570 \mathrm{~mm}$ of precipitation per year, the bulk 
occurring during its short wet season between December and March. The dry season makes up the remainder of the year [19].

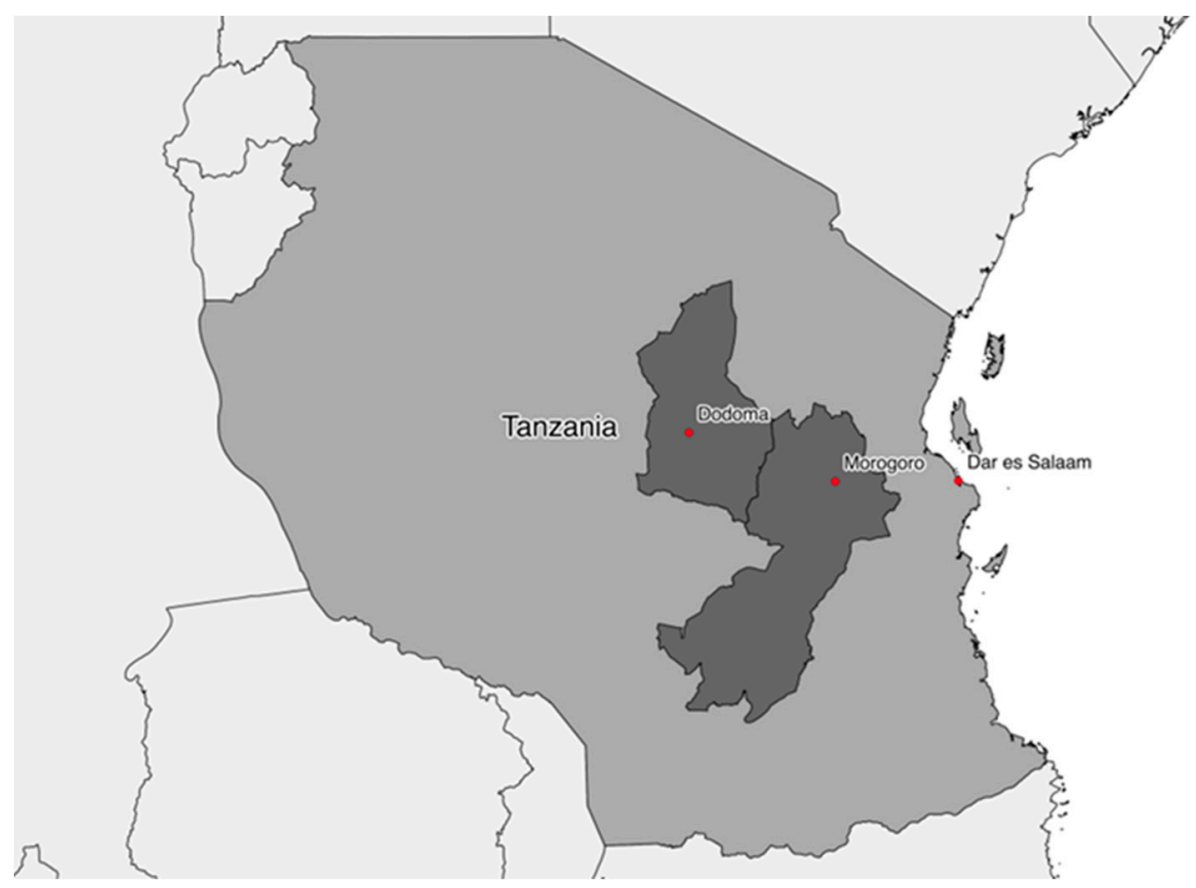

Figure 1. Map of Dodoma region, Tanzania. Source: Scale-N project data.

Exploring the possible origins of power structures and gender roles in the region, we found that Dodoma has a mixed cultural structure; the population is composed of descendants from different clans. Historically, these were predominantly patrilineal and pastoralist, practicing settled agriculture or migrating to urban areas throughout Tanzania. The clans moved around, adopting new habits and family configurations. Traditionally, the definition of a prosperous man was a man who had more than one wife [20].

This work focused on two remote rural Tanzanian villages, namely Chinoje and Mzula, in Chamwino district, Dodoma region. Chamwino is among the 65 districts in Tanzania with high levels of famine. This area lies on the central plateau of Tanzania, in the western bearing along Dar es Salaam Dodoma road. The main tribes in Dodoma region are the Gogo, the Warangi, and the Wasandawi.

These specific villages were selected because of their severe status concerning food insecurity, malnutrition, and vulnerability according to the Department of Food Technology, Nutrition and Consumer Sciences (DFTNCS) at Sokoine University of Agriculture (SUA) in Tanzania. Chinoje, $60 \mathrm{~km}$ from Dodoma town, has 629 households. Mzula, $30 \mathrm{~km}$ from Dodoma town, has a total of 750 households (Scale-n.org). Chinoje and Mzula grow pearl millet, but also grain legumes: cowpeas, green gram, and Bambara nuts. Some vegetables are produced in the ephemeral sand riverbeds during the dry season, which lasts for only four months. Fruits are rare in Chinoje, with a few mango and pawpaw trees found in the village. In Mzula, sesame is grown by $70 \%$ of the population, despite being blamed for accelerating deforestation in the mountains. Sorghum, maize, and sunflower are cultivated by $60 \%$ and $40 \%$ of the populations in Chinoje and Mzula, respectively. In home gardens, vegetables and peanuts are popular, with $70 \%$ of the population cultivating these. Unlike Chinoje, in Mzula, fruits are widely grown, including mango and pawpaw. In Chinoje, there are few safe water sources for the community and not everyone can access them. Most people depend on the extraction of domestic water from sand rivers. A few families keep cattle or chickens, which are usually sold to help with basic consumer purchases. A typical meal in this region is mostly starchy, typically consisting of ugali served with some vegetables as a relish. In the relish, typically local (non-iodized) salt and oil or groundnuts are added (Scale-n.org). 
Women in Chinoje and Mzula presented a malnutrition scenario in which 19-21\% of women were overweight/obese, but where anemia (11-17\%) and/or iron deficiency (15-17\%) were also frequent [21]. The high prevalence of anemia and deficiency of micronutrients is common in Sub-Saharan Africa and is associated with an unbalanced diet consisting mainly of cereals, very few animal products, and the insufficient micronutrient content of yellow and orange fruits and vegetables [21]. In addition to the difficult biophysical conditions, this is associated with food consumption and its distribution at the household level.

\subsection{Methods}

The methodological procedures were carried out in two phases: (1) a face-to-face survey with structured interviews of 333 households, and (2) workshops based on TO-Theater of the Oppressed [22,23]. These two procedures were complemented by three research stays between January 2016 and January 2018.

Research participants were selected from family farmers registered in the region and invited to participate by the Sokoine University of Agriculture and the Scale-N project (scale-n.org). The main objective of Scale-N is to safeguard food and nutrition security for the local Tanzanian population by supporting the development of diversified and sustainable agriculture. The research concept of Scale-N includes: (1) local stakeholder involvement from the outset of the project and integrated into most analytical steps; (2) in-depth analysis of the nutritional status and social conditions of the local population as well as their access to sanitation and health care; (3) an integrated in-depth analysis of nutrition value chain components to identify nutrient dense plant-derived foods, with regard to sustainable resource management and production conditions; (4) participatory field testing of the most promising nutrient-sensitive innovations; (5) local implementation of nutrient-sensitive innovations focusing on capacity building; and (6) dissemination and policy implementation of lessons learned. This study was part of step (2), investigating social conditions in detail, and focused on community problems and gender roles.

In the first phase, data were collected from households in the two selected villages of Dodoma. Households qualified for participation in the Scale-N project activities if they had at least one child in grades three to six (including their mothers (Children/mother pairs were included in anthropometric measures of nutritional status of the local population. A nutritional status survey was conducted in parallel to this study.) or a representative parent or guardian for each participating child). Face-to-face structured interviews with 333 households, using questionnaires, were conducted to collect demographic and socio-economic information as well as other relevant information focusing on understanding the local problems and food perceptions. The information documented during the survey was summarized in reports containing observations, recorded statements, tables, and calculations for each village. Through this methodological step, the initial data regarding main community problems were collected. From these data, the selection of five specific community problems (the five most important, based on interviews) was possible. These problems were discussed in depth in the second step.

In order to understand how residents perceived their problems, workshops based on TO-Theater of the Oppressed [22] — enabled us to refine the data and to understand social contexts, power tensions, and proposals to improve food security. The games and improvisations initiated by TO facilitated an understanding of how farmers' perceived their food insecurity conditions. The workshop aimed to enact the ideas from dialogues and narratives through images, scenes, and music.

Theater of the Oppressed (TO), developed by Augusto Boal [22,23], is a form of popular community-based education that uses theater as a tool for social change. As Boal [22] proposed, the audience is active, the play is collective, and the "spect-actors" explore, show, analyze, and transform the reality in which they are living. TO techniques are a complex, interdisciplinary, and multivocal, incorporating philosophical knowledge encompassing, among others, the work of educator Paulo Freire. Therefore, workshop activities were conceptualized and designed by following the 
concepts (limit-situations and viable-unknowns) of the Pedagogy of the Oppressed, written by Paulo Freire [24]. Freire's critical approach in the education domain was intended to give people the tools to identify and question the validity of knowledge forms and social structures by helping them develop critical consciousness about their own realities [25]. Freire's Pedagogy of the Oppressed is widely used, especially in South Africa and Kenya, to debate community health and the development problems of communities [25-27].

"Conscientization", a Freirean concept, deals with the political dimension of education $[24,25,28]$. The process of community empowerment and development is a political action, where education has a role in the development of critical consciousness within vulnerable populations. Therefore, communities can increase their possibilities for critically understanding their living conditions, potentially becoming active in forming solutions to their own needs.

The workshops held in the Chinoje and Mzula villages focused on the interpretation of community challenges and local problems related to food security in daily life. A total of 130 people attended eight workshops (four workshops per village, based on four categories: one workshop only for women, one workshop only for men, one workshop for women/men together, and one workshop for children).

Workshops were developed based on the 3 principles of action (RUV): Recognize the existing community knowledge and preferences; Understand systemically the "realities" of the problems lived by the community; and, Visualize new possibilities and strategies to transform their realities. Each workshop comprised six steps: (1) introduction; (2) ice-breaking/warming by identifying community's preferences; (3) systemic analysis of local problems as a "limit-situation" [24] (Freire, 2018); (4) finding local solutions/ viable-unknowns together; (5) evaluating the solutions; and (6) evaluating the effectiveness of the methods/workshop [25]. Steps 1 and 2 explored the community's preferences for food and social activities. Steps 3 and 4 focused the central idea of TO, especially the forum theater technique [22], giving the audience the opportunity to propose a transformation of the problem on stage. Participants were divided into two groups, one formulating the scene about the community problem and the other (the audience) explaining who the people involved were, what happened to them, why they were facing the problem, and how it could be changed. Step 5 was based on a collective discussion about the solutions proposed.

Each workshop lasted about two hours. Participants received symbolic compensation of one kilogram of food, equivalent to one Euro, for their time and for leaving their farming activities. As Dodoma region is highly diverse with regards to tribes and languages spoken, collaboration with translators and regional facilitators was essential, not just for verbal communication, but also cultural translation. Two Tanzanian facilitators, one non-Tanzanian mediator, and one Swahili translator, participated in each workshop. The workshop team was selected based on their professional experience and familiarity with the case study. We provided training on research methods, including TO principles, conducting forum theater techniques, using digital voice recorders, observing people subject matters, and research ethics. The research was conducted as part of the Scale-N project, a research collaboration between the Leibniz Centre for Agricultural Landscape Research (ZALF) in Germany and Sokoine University of Agriculture in Tanzania. The study had the ethical approval of the Sokoine University of Agriculture in Tanzania and all case study participants gave their consent for inclusion before participating in the study. The anonymity of all interviews and workshop participation was ensured.

Chinoje and Mzula are both difficult to access—no roads reach either community. The landscape is composed of a few houses made from different materials, including brick, wood, earth, and thatch. Because each village is isolated, farmers walked many kilometers to village centers in order to attend and participate in the workshops. Village centers typically have a school, a community center, and a health center. Workshops were held in the village school classroom.

To analyze the results, workshops were recorded with the permission of the respondents. The workshops resulted in $17 \mathrm{~h}$ of recorded video. The recordings were partially transcribed and analyzed through the identification of full narratives, recurrent words (or symbols), contradictions (variation), and subtle details (silences and hesitations). In addition, the collected data were analyzed 
in depth by creating community mental maps [29]. In this research, "mental mapping" refers to the elaboration of a map that enabled us to collect, organize, store, and recall the information previously delivered verbally by the participants about their spatial environment. These mental maps facilitated the investigation and description of social representation and collective symbols of the experienced and imagined spatial environment [30] of project participants. In total, we elaborated 36 mental models to understand local perceptions of the problems, then connected them with gender roles and structures.

\section{Results}

In this work, in the results related to the survey of community problems and to the TO workshops, we focused on the distinction between male and female responses, specifically those aspects that are most important for gender studies, including subcategories such as malnutrition, food behavior (unequal distribution), and violence (physical and/or subtle aggression) in the context of food security. As this work was configured as an analysis of the results collected in the field by research on food security, several aspects of the contextual factors of malnutrition were found and are already published (see $[21,25,31])$.

During the first methodological phase, the survey, it was possible to explore community problem perceptions quantitatively. At the household level in Mzula, $48.5 \%$ of caregivers reported that food was the major challenge, followed by money $(22 \%)$, water $(11 \%)$, disease $(10 \%)$, conflicts $(3 \%)$, and land $(4 \%)$. The magnitude of these challenges differed across the two villages (Figure 2). At the household level in Chinoje, $69.3 \%$ of caregivers reported that food was the major challenge, followed by money $(15.7 \%)$, water $(9.6 \%)$, disease $(3.6 \%)$, land $(1.2 \%)$, and conflicts $(0.6 \%)$.
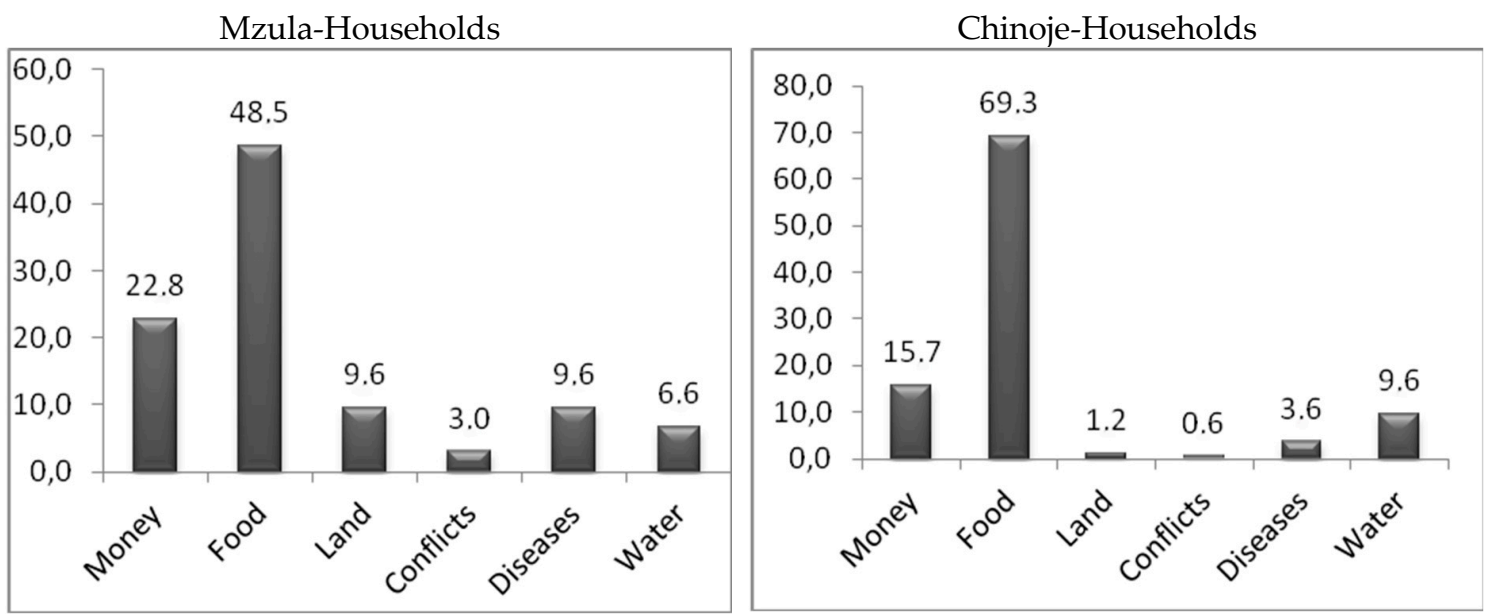

Figure 2. Leading perceptions of local problems at household level (per village).

As shown, at the household level, food was perceived as the principal problem, followed by money (Figure 2). At the village level, money and land, followed by conflict, were perceived as the principal problems. For the two villages, hunger was considered to be a household problem rather than a community problem.

As shown, at the village level, results about local problems differed. In Mzula, money and land were identified as the main problems (Table 1). This can be explained by the descriptions of workshop participants regarding conflict related to land tenure and heritage in this village. According to Chinoje participants, the main village problem was water. This can be related to the high incidence of severe drought in this village. The problem of water scarcity was identified as one of the main reasons for food insecurity during the pedagogical workshops. 
Table 1. Local problem perception at village level.

\begin{tabular}{ccccc}
\hline & \multicolumn{2}{c}{ Mzula } & \multicolumn{2}{c}{ Chinoje } \\
\hline Description & $\boldsymbol{N}$ & $\boldsymbol{\%}$ & $\boldsymbol{N}$ & $\boldsymbol{\%}$ \\
\hline Money & 37 & 22.2 & 22 & 13.3 \\
Land & 40 & 24.0 & 08 & 4.8 \\
Conflicts & 25 & 15.0 & 11 & 6.6 \\
Diseases & 08 & 4.8 & 02 & 1.2 \\
Water & 18 & 10.8 & 94 & 56.6 \\
Food & 05 & 3.0 & 11 & 6.6 \\
Infrastructure & 08 & 4.8 & 04 & 2.4 \\
Unreliable rainfall & 11 & 6.6 & 01 & 0.6 \\
Inadequate Health facilities & 08 & 4.8 & 10 & 6.0 \\
Drought & 04 & 2.4 & 02 & 1.2 \\
Thieves & 01 & 0.6 & 01 & 0.6 \\
No existing problem & 02 & 1.2 & 00 & 0.0 \\
Total & $\mathbf{1 6 7}$ & $\mathbf{1 0 0}$ & $\mathbf{1 6 6}$ & $\mathbf{1 0 0}$ \\
\hline
\end{tabular}

As the first step of the research design was rather quantitative, problems were explored, isolated, and classified by order of importance. The five top problems (money, land, conflicts, diseases, water, and food) were then explored qualitatively through pedagogical workshops, addressing men, women, and children separately, as well as through one mixed gender group.

According to the majority opinion of workshop participants in Chinoje and Mzula, food insecurity was mainly related to water restrictions and land use management. It was clear that food production depended on water availability and accessibility, as well as on soil conditions and land tenure distribution. Workshop participants reported that water scarcity was the main source of food production problems and was also related to disease and money problems. Consequently, water management lay at the heart of most of the local solutions to the food production problem, proposed by both men and women.

However, men and women reported different issues related to water: men focused on problems associated with infrastructure and rain scarcity during the dry session, while women noted that water was a source of community conflicts regarding priority in water collection queues.

Figure 3 depicts food security issues at the community level as identified by the participants in the first phase: (1) land use; (2) water; (3) diseases; (4) money; and (5) conflicts. At the household level, there were further issues, including gender issues, related to food insecurity (second research phase), as shown in the outer circle: (1) small crops; (2) children going hungry; (3) men traveling/leaving home; (4) women staying home alone; and (5) violence.

As shown in Figure 3, community members explained that for each driver of food insecurity (money, diseases, water, conflicts, and land), there was a series of issues related to gender that systemically reinforced the current food insecurity situation at the household level. Workshop participants frequently reported that men left the house to obtain food from other regions. Since the prospects for cultivation were very low, due to unfavorable soil and climate, men left the village to seek food and work. Women then stayed at home alone, taking care of the family. This reinforced classic gender roles and expectations, as discussed by Feinstein [7].

As a general overview of the results, the scenes (workshop step 3) showed that all five problems were interconnected. Participants (men, women, and children) explained that food distribution at the household level was not equal, but this was not associated with malnutrition (unequal nutrition) or conflicts. Children in this step showed that hunger was generally connected with other behaviors, such as parents stealing food to use to buy alcohol. Children also reported that domestic violence was a community issue. All participants associated domestic violence with alcoholism, while children associated alcoholism with both men and women, simultaneously. 


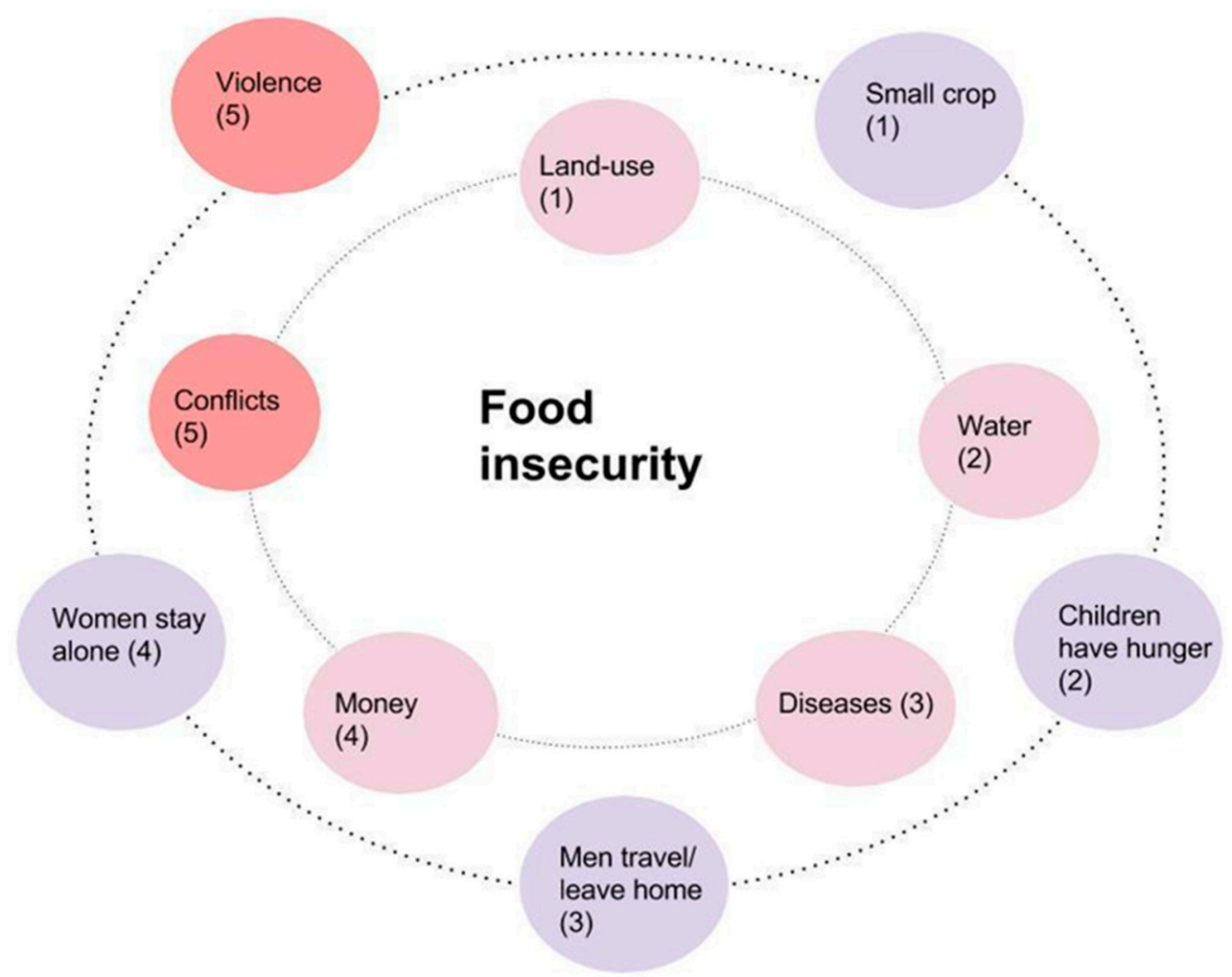

Figure 3. Main- and sub-drivers, along with flows, in the food insecurity situation for the communities of Chinoje and Mzula (Dodoma).

During the workshops attended by women, respondents described a broad continuum of violent experiences (physical and/or subtle) and social practices, including food choices and food practices. Femininities were associated with submission, having less meat to eat, being the last to eat, and also with staying at home when men traveled to find work and money during times of hunger. For women and children, the man/father should receive the first choice of food, including significantly more meat. Only then did women and children receive their share of food. Some women pointed out that the men receiving more food (especially meat) was an expression of love for the men.

- "First the man eats the meat, then children, then the woman" (Woman, Dodoma, 2016).

When the workshops were exploring conflict, women in Chinoje explained that, at the household level, (s)he who controlled the crops had the power. They explained that men controlled the crops, using the proceeds for money and alcohol. This situation caused several conflicts, including domestic violence. They explained that they could not find options for help because village leaders were men, with men protecting each other.

With respect to violence, in the TO workshops attended by women only, the dominant explanation was that the men stole food and the women had fewer opportunities in general:

- "There is no one to talk to ask for help (... when you have domestic violence ... ) because men are friends and the leaders too" (Woman, Dodoma, 2016);

- "Credits (financial) should be given to women. We can do our activities" (Woman, Dodoma, 2016);

- "Men stole food to trade for alcohol" (Woman, Dodoma, 2016).

In the workshop attended by men only, they talked about how increasingly empowered women were taking power at the household level, leading to domestic conflicts (see quotes). Masculinities were associated with decision-making power. The claim, "they came home over empowered," and, consequently, the claim that "we have to beat them," exemplified this. 
Men reported that women come home over-empowered after participating in educational training on health and nutrition. During the activities, they pointed out things like a "lack of respect" and the fact that their "ideas [are] disregard by women." These comments about over- empowerment reflect the characteristics of a patriarchal society in which a woman should not disagree with her husband's ideas and is forced to maintain a passive stance in the face of his domination. When asked about solutions to these problems, some men suggested more training about communication as a solution for their issues arising from violence and communication problems:

- "After nutrition education, they (... women ... ) come home over empowered" (Man, Dodoma, 2016);

- "We have to beat them" (Man, Dodoma, 2016);

- "Women do not respect their men" (Man, Dodoma, 2016);

- "Men should be included in the activities" (Man, Dodoma, 2016);

- "We need training in better communication with our community" (Man, Dodoma, 2016).

The Dodoma community narratives revealed several contextual factors related to food insecurity [25,32], thus enabling us to better understand food insecurity and malnutrition in complex situations, interconnecting it with not just gender roles but also other factors. The methods applied provided the opportunity to observe the multiple and conflicting values inherent in socioenvironmental problems [33].

\section{Discussion}

By exploring how Tanzanian subjectivities were related to food insecurity and the genders constituted and interrelated, the results showed that women lived within a complex set of domestic relationships between violence, food, and malnutrition. Domestic rules showed forms of masculinities and femininities that influenced the malnutrition status. However, malnutrition in these villages had multidimensional causes [25,34].

Violence associated with food distribution was a common issue that can be associated with the traditional male roles in these communities. Male domination and the consequential female subordination [35] were the elements that constituted masculinities and femininities in food behaviors. The USAID report [36] demonstrated that many forms of gender-based violence are normalized in Tanzania. Young females are taken out of school to assist with domestic responsibilities or to marry. The inequities in access to education leave women economically dependent upon their male partners. Women also do not report abuse due to feelings of shame. In this sense, we question the underlying meanings of socialization that could lead to violence against women and violence in general. Feminist theory defines violence against women as a reflection of the segregation of gender roles, allowing this phenomenon to be related to a system of female subjugation. In this sense, feminist contributions are particularly important in associating violence against women with gender inequalities and a patriarchal hierarchical social system, as found in Tanzania.

As shown in the results, in the narratives of women and children, the man/father was the one who should receive the first share of the food and also the more significant quantity of meat. Secondly, the children and women should receive their share after the men. Consistent with the finding of Lenz [1]), this can be considered violence in the form of food norms; especially in our case study, where $30 \%$ of women were malnourished [21].

In Tanzania, traditional gender constructions limit the influence and activities of women to the household level, where domestic labor, childbearing, and child-rearing dominate [37]. Even at this level, women in Dodoma did not have unlimited control. Their femininities expressed that the prioritized individuals, men, should eat, be satisfied, and eat more meat. Therefore, the socially constructed definitions of being a "woman at the table" in our case study were related to eating later, eating less, and eating less meat. These were the tactics through which women coped with oppression and submission. Tactics describe the strategies that people with little power use to set the rules of the game [1]. 
On the other hand, women in the workshops did not describe and directly relate their food practices as being a way to avoid violence; rather they considered this tactic to be a signal of love. This can be linked with what [37] noted as persistent inequalities between men and women, which are often covered by referring to gender norms and traditions, including violence.

A study by Schlindwein et al. [38] of masculinities related to labor in Dodoma region also showed that female roles were principally attached to food preparation, including the collection of firewood. One major obstacle for achieving gender equality is the prevalence of existing social and cultural norms that create barriers for the empowerment of rural women. Generally, women are responsible for feeding the family, giving them less free time to work, study, or participate in other social activities.

Bundala et al. [34] showed that food attitudes and practices were also precarious in this region. These can reinforce the problem of household food distribution and iron deficiencies because women eat less meat, even though women and children are potentially the ones who need more. In this regard, other actions that are aligned with the existing masculinities and femininities could improve the malnutrition status. For example, kitchen gardens, an activity associated with women, can increase the production of nutritious vegetables. These generate green leaves, the intake of which can reduce the iron deficit. While finding gender and nutrition sensitive strategies for food insecurity are important, it is crucial to identify existing social and cultural norms that inhibit the empowerment of malnourished women. Women in highly constrained environments make choices that help them navigate violence, but that also affect their own nutritional and food security. These strategies, not well-documented in the existing literature [1], reveal the complex trade-offs that women make and the limitations they face.

By analyzing the results and potential pitfalls of food security project interventions, it is possible to conclude that it is necessary to rethink these models of socialization, instead seeking to involve both women and men in discussions regarding food security and nutrition. In 2000, Tanzania adopted several actions that included gender mainstreaming in government policies. The country also reinforced international human rights protocols. However, the national machinery for implementing these gender goals is still constrained. Following the Beijing Platform for Action, the Millennium Development Goals, and cognizant of the need to set clear targets in each area, the Tanzanian Government prepared its sub-program for Women's/Gender Advancement (1997-2003).

Gender roles in agricultural practices in developing countries are deep-seated, often based on traditions, race, social status, marital status, and age [5,39]. The gendered roles in agriculture and food security are rooted in social and cultural norms that need to be challenged through more gender-sensitive policies and women's empowerment. The key question here is whether the programs are prepared to deal with the identification, integration, and reformulation of masculinities and femininities because these are the part of the enabling environment where women's empowerment should occur. The literature also acknowledges that gender equality has been as much a political project as a technical project, with efforts directed toward creating "voice" [40] and direct influences on the ground.

Enhancing women's empowerment is seen as a strategy that increases household nutrition and food security [41,42]. As stated by True [43], feminist political and legal theory provided the gender perspective for the women's human rights movement and for making violence against women in the private spheres visible. While this resulted in some advances for the women's empowerment movement, it also tended to detach violence against women from the broader struggle for social and economic equality, resulting in it being perceived as a female problem rather than a systemic problem affecting all individuals and social groups [44]. Food security and nutrition projects embedded in this context must reconsider their approaches, and work to understand how to best achieve their objectives within realities that involve violence at the local level.

The problem must be addressed with public policies that incorporate a better understanding of the contextual factors underlying food insecurity and that involve both men and women, starting from childhood. This includes activities involving people of different ages-from school-age through 
young adulthood-as well as motivating men to engage in gender equality discussions and to take responsibility for sexual and reproductive health as well as nutritional issues.

From the results, it is possible to show that knowledge development in food security projects that interferes with household practices and power structures must first develop an environment where knowledge can be expressed safely. Food security and nutrition practices can then be transformed without inadvertently changing social structures and triggering an increase in domestic violence. It is essential to avoid propagating negative effects of nutrition education, while supporting women in the empowerment process.

The next step is to encourage non-violent methods for conflict resolution in projects supported by national and regional policies. Here, transdisciplinarity plays a crucial role. Simultaneously strengthening the capacity of both law enforcement and the judiciary to prevent and respond to domestic violence is important. While men in the workshops showed that violence is normalized, women declared they did not have anybody to ask for help when experiencing domestic violence. Multiple voices should be employed to inform all men that violent responses are never appropriate. For example, violent actions could result in men being required to attend educational activities. In addition, as women in the workshops suggested, community leaders should be trained to handle such cases. In this sense, interdisciplinary groups, involving areas as diverse as health, psychology, law, and human rights are crucial for increasing awareness.

Finally, regarding the challenges of this research, although the participants evaluated the workshops as providing an important opportunity to freely express themselves, hidden messages, silences, and assumptions could occur since our findings were not based on methods specifically targeting masculinities, femininities, and violence. We find that more studies on masculinities and femininities are necessary to understand, in the context of food insecurity, how women and men make conscious choices about their food and nutrition security within the wider context of hunger and poverty. Furthermore, other kinds of violence should be identified in studies conducted directly in the domestic environment.

Understanding and working on the resignification of male and female identities is also a research area missing from the food security projects embedded in contexts, like the one presented here. Studies on masculinities in Africa suggest that, in addition to patriarchal traditions, Tanzanian men also face the weight of years of colonialism [45], potentially expressing a need to reconstruct their identity and define national sovereignty through the "rehabilitation of masculinity" [45].

\section{Conclusions}

We are convinced that the definitions of Tanzanian masculinities and femininities are not monolithic. Thus, this study cannot be extended to all men in Tanzania, understanding them as holders of immutable and uniform behaviour. We understand that gender roles and power structures are social constructs. For this reason, we tackled the issues of food security and masculinities in an interdisciplinary way, bringing together areas of nutrition, anthropology, and education. We used the techniques of the Theater of the Oppressed, which enabled us to better understand different gender realities and to capture community narratives. The method was effective, as it promoted sharing of personal stories and opened dialogue on conflicts, violence, and gender roles in the context of food security. This study also contributes to the production of scientific knowledge useful for addressing marginalization, violence, and hunger. Through an in-depth qualitative analysis of existing problems and practices based on a case study approach, this study contributes to the ongoing debate over gender, violence, and food security, with a specific focus on the complexity of the interrelations. However, more research is necessary to better understand the connections between power structures, masculinities, and femininities within the context of food insecurity.

This research shows that, in some contexts, understanding gender roles is significant in the malnutrition transformation for the entire family. Masculinities and femininities are closely linked with current malnutrition status but cannot be considered as single factors. These compound a network of 
contextual factors that food security programs must better understand. From the scientific perspective, and as shown in this study, research on the contextual factors of food insecurity is a complex and transdisciplinary process involving not just several uncertainties, but also identifiable but intangible issues. As Hossain [46] and Gaventa [47] pointed out, investigating the role of power in creating nutrition insecurity means not just making sense of its different forms, not all of which are quantifiable, but also understanding the multiple levels and food system spaces where power is at play. We agree with them that policymakers should consider such analyses-which can highlight gaps in areas for action, thinking, and necessary allies-when formulating realistic nutrition policies and interventions that respect complex cultural systems.

Nutrition education researchers understand the importance of cultural and contextual factors in nutritional status. Our research suggests that understanding the links between gender roles and malnutrition in more depth is important for both nutritional outcomes and, potentially, interventions related to food security. By analyzing the results and potential pitfalls of food security project interventions, it is possible to conclude that malnutrition at the household level involves multiples factors related to masculinities and femininities, among others. Therefore, it is necessary to identify and rethink the community models of socialization (values, rules, attitudes, ideologies, social structures), and seek to involve both women and men in discussions about food security and nutrition.

Author Contributions: M.B. and and I.S. contributed conception and design of the study; M.B., J.B. and I.S. organized the database and performed the analysis; M.B. and J.B. the first draft of the manuscript, S.S. and C.R. critically review and edit sections of the manuscript. All authors contributed to manuscript revision, read and approved the submitted version.

Funding: This research was funded by Scale-N project (2016-2018) under the German Federal Ministry of Food and Agriculture (BMEL), based on the decision of the Parliament of the Federal Republic of Germany.

Acknowledgments: We thank the workshop participants in Dodoma who shared their time and their life perspectives. We also thank the translators for facilitating mediation during the activities performed in the villages. This work—embedded in the Scale-N project (http://www.scale-n.org)—was supported financially by the German Federal Ministry of Food and Agriculture (BMEL), based on the decision of the Parliament of the Federal Republic of Germany.

Conflicts of Interest: The authors declare no conflict of interest.

\section{References}

1. Lentz, E.C. Complicating narratives of women's food and nutrition insecurity: Domestic violence in rural Bangladesh. World Dev. 2018, 104, 271-280. [CrossRef]

2. FAO. Tanzania Mainland Country Profile: Gender Inequalities in Rural Employment in Tanzania Mainland, an Overview; FAO: Rome, Italy, 2014.

3. United Republic of Tanzania, National Panel Survey 2010-2011. National Bureau of Statistics Nationa Bureau of Statistic. Available online: https://www.ilo.org/surveydata/index.php/catalog/488/overview (accessed on 10 March 2017).

4. National Bureau of Statistics (NBS) and United Nations Children's Fund (UNICEF). Child Poverty in Tanzania based on 2014/2015 National Panel Survey_Summary Report; NBS and UNICEF: Dar es Salaam, Tanzania, September 2018.

5. Agarwal, B. Food Security, Productivity, and Gender Inequality; IEG Working Paper No. 320; Institute of Economic Growth: New Delhi, India, 2012.

6. Agarwal, B. Food Crises and Gender Inequality, DESA Working Paper, UN Department of Economic and Social Affairs, New York. 2017. Available online: http://www.un.org/esa/desa/papers/2011/wp107_2011.pdf (accessed on 10 January 2017).

7. Feinstein, S.; Feinstein, R.; Sabrow, S. Gender Inequality in the Division of Household Labour in Tanzania. Afr. Sociol. Rev. 2011, 14. [CrossRef]

8. Mollel, N.M.; Mtenga, N.A. Gender roles in the household and farming systems of Tchenzema, Morogoro-Tanzania. S. Afr. J. Agric. Ext. 2000, 29, 73-88.

9. Mead, M. Sexo e Temperamento em Três Sociedades Primitivas; Perspectiva: São Paulo, Brazil, 1988. 
10. Scott, J.W. Gender and the Politics of History—30th anniversary edition; Columbia University Press: New York, NY, USA, 2018; 263p.

11. Bellows, A.C. Violence and women's participation in the right to adequate food and nutrition. In Gender, Nutrition, and the Human Right to Adequate Food: Toward an Inclusive Framework; Bellows, A.C., Valente, F.S.L., Lemke, S., de Lara, M.D.N.B., Eds.; Routledge, Taylor and Francis Group: Abingdon-on-Thames, UK, 2016; pp. 108-161.

12. Msuya, F.M. Resistance, Freedom, Nation-Building: Reminiscences of the German Colonial past in Tanzania. In German Colonialism: Fragments, Past and Present; Gottschalk, S., Ed.; Stiftung Deutsches Museum: Berlin, Germany, 2016.

13. Maddox, G.H.; Giblin, J.L. Search of a Nation: Histories of Authority E Dissidence in Tanzania; James Currey: Oxford, UK, 2005.

14. CENSUS 2012 POPULATION AND HOUSING CENSUS Population Distribution by Administrative Areas Tanzania. Available online: http://www.tzdpg.or.tz/fileadmin/documents/dpg_internal/dpg_working groups_clusters/cluster_2/water/WSDP/Background_information/2012_Census_General_Report.pdf (accessed on 10 January 2017).

15. Mazengo, R. Assessment of the effectiveness and sustainability of household food insecurity coping strategies in Chamwino District Dodoma Region. Master's Thesis, Sokoine University of Agriculture, Morogoro, Tanzania, 2011.

16. Curtin, P.D. Cross-cultural Trade in World History; Cambridge University Press: Cambridge, UK, 1984.

17. URT/CFSVA-United Republic of Tanzania Comprehensive Food Security and Vulnerability Analysis (CFSVA). 2009. Available online: https:/reliefweb.int/sites/reliefweb.int/files/resources/ F3BFDF4DA91FB415C12577BC003B7E57-Full_report.pdf (accessed on May 2019).

18. FAO: Food and Agriculture Organization. An introduction to the basic conceptsof food security. In Food Security Information for Action Practical Guides; EC-FAO Food Security Programme: Rome, Italy, 2008. Available online: http://www.fao.org/3/a1936e/a1936e00.pdf (accessed on 24 March 2016).

19. Kahimba, F.C.; Mutabazi, K.D.; Tumbo, S.D.; Masuki, K.F.; Mbungu, W.B. Adoption and scaling-up of conservation agriculture in Tanzania: Case of Arusha and Dodoma regions. Nat. Resour. 2014, 5, 161-176. [CrossRef]

20. Mnyampala, M.E. The Gogo: History, Customs, and Traditions. Trans, and Introduced by Gregory Maddox; M. E. Sharpe: Armont, NY, USA, 1995.

21. Stuetz, W.; Gowele, V.; Kinabo, J.; Bundala, N.; Mbwana, H.; Rybak, C.; Biesalski, H.K. Consumption of Dark Green Leafy Vegetables Predicts Vitamin A and Iron Intake and Status among Female Small-Scale Farmers in Tanzania. Nutrients 2019, 11, 1025. [CrossRef] [PubMed]

22. Boal, A. The Rainbow of Desire: The Boal Method of Theatre and Therapy; Routledge: Abingdon-on-Thames, UK, 2013.

23. Boal, A. Theatre of the Oppressed (Trans. C.A. and M.O.L. Mc Bride); Urizen Books: New York, NY, USA, 1979.

24. Freire, P. Pedagogy of the Oppressed; Bloomsbury publishing: New York, NY, USA, 2018.

25. Bonatti, M.; Schlindwein, I.; Lana, M.; Bundala, N.; Sieber, S.; Rybak, C. Innovative educational tools development for food security: Engaging community voices in Tanzania. Futures 2018, 96, 79-89. [CrossRef]

26. Odhiambo, C. Theatre for Development in Kenya: in Search of An Effective Procedure and Methodology. Ph.D. Thesis, Stellenbosch University, Stellenbosch, South Africa, December 2005.

27. Santos, B. Teatro do Oprimido-Raízes e Asas: Uma teoria da Práxis; IBIS LIBRIS: Rio De Janeiro, Brazil, 2016.

28. Mejía, A. The problem of knowledge imposition: Paulo Freire and critical systems thinking. Syst. Res. Behav. Sci. 2004, 21, 63-82. [CrossRef]

29. Gregory, D.; Johnston, R.; Pratt, G. Dictionary of Human Geography: Mental maps/Cognitive Maps, 5th ed.; Wiley-Blackwell: Hoboken, NJ, USA, 2009; p. 455.

30. Tuan, Y.F. Images and mental maps. Ann. Assoc. Am. Geogr. 1975, 65, 205-212. [CrossRef]

31. Bonatti, M. Social Learning and Community-based Strategies to Promote SUSTAINABLE Development Goals (SDGs). 2018. Available online: https://edoc.hu-berlin.de/handle/18452/20303 (accessed on 10 March 2019).

32. Contento, I.R. Nutrition education: Linking research, theory, and practice. Asia Pac. J. Clin. Nutr. 2008, 17, 172-175. Available online: http://apjcn.nhri.org.tw/server/APJCN/17/s1/176.pdf (accessed on 20 May 2018).

33. Ingram, M.; Ingram, H.; Lejano, R. Environmental action in the anthropocene: The power of narrative networks. J. Environ. Policy Plan. 2015, 1-16. [CrossRef] 
34. Bundala, N.; Joyce Kinabo, J.; Jumbe, T.; Bonatti, M.; Rybak, C.; Sieber, S. Gaps in knowledge and practice on dietary consumption among rural farming households; A call for nutrition education training in Tanzania. 2019, manuscript submitted.

35. Bourdieu, P. Masculine Domination; Polity Press: Cambridge, UK, 2001.

36. USAID Health Policy Initiative. Gender-Based Violence in Tanzania: An Assessment of Policies, Services and Promising Interventions Task Order; USAID Health Policy Initiative: Washington, DC, USA, 2008. Available online: http://pdf.usaid.gov/pdf_docs/PNADN851.pdf (accessed on 10 March 2017).

37. Laisser, R.M.; Nyström, L.; Lugina, H.I.; Emmelin, M. Community perceptions of intimate partner violence-a qualitative study from urban Tanzania. BMC Women's Health 2011, 11, 13. [CrossRef] [PubMed]

38. Schlindwein, I.; Bonatti, M.; Bundala, N.; Naser, K.; Löhr, K.; Hoffmann, H.; Sieber, S.; Rybak, C. Perceptions of time-use in Rural Tanzanian Villages: Working with Gender-sensitive Tools in Nutritional Education Meetings. 2019, manuscript submitted.

39. Sachs, C.; Alston, M. Global shifts, sedimentations, and imaginaries: An introduction to the special issue on women and agriculture. Signs J. Women Cult. Soc. 2010, 35, 277-287. [CrossRef]

40. Mukhopadhyay, M. Mainstreaming gender or "streaming" gender away: Feminists marooned in the development business. In The Palgrave Handbook of Gender and Development; Palgrave Macmillan: London, UK, 2016; pp. 77-91.

41. Galiè, A.; Teufel, N.; Girard, A.W.; Baltenweck, I.; Dominguez-Salas, P.; Price, M.J.; Smith, K. Women's empowerment, food security and nutrition of pastoral communities in Tanzania. Glob. Food Secur. 2019, 23, 125-134. [CrossRef]

42. Verhart, N.; Van Den Wijngaart, A.; Dhamankar, M.; Danielsen, K. Bringing agriculture and nutrition together using a gender lens. 2012. Available online: https://www.securenutrition.org/sites/default/files/resources/ attachment/english/SNV\%20KIT\%20-\%20agriculture\%20nutrition\%20gender\%20-\%202015.pdf (accessed on 20 May 2019).

43. True, J. The Political Economy of Violence Against Women: A Feminist International Relations Perspective. Aust. Fem. Law J. 2010, 32, 39-59. [CrossRef]

44. PWESCR-Programme on Women's Economic, Social and Cultural Rights. 2010. Available online: www.pwescr.org (accessed on 20 March 2019).

45. Ouzgane, L.; Robert, M. African Masculinities: Men in Africa from the Late Nineteenth Century to the Present; Springer: Berlin, Germany, 2005.

46. Hossain, N. Inequality, Hunger, and Malnutrition: Power Matters; International Food Policy Research Institute, Welthungerhilfe, and Concern Worldwide: Dublin, Ireland, 2017.

47. Gaventa, J. Finding the spaces for change: A power analysis. Ids Bull. 2006, 37, 23-33. [CrossRef] 